\title{
The transcriptome variations of Panax notoginseng roots treated with different forms of nitrogen fertilizers
}

\author{
Xiaohong Ou ${ }^{1,3 \dagger}$, Shipeng $\mathrm{Li}^{1,2+}$, Peiran Liao ${ }^{1}$, Xiuming Cui ${ }^{1}$, Binglian Zheng ${ }^{5}$, Ye Yang ${ }^{1 *}$, Dahui Liu ${ }^{*}$ \\ and Yun Zheng ${ }^{2^{*}}$ (1)
}

From International Conference on Bioinformatics (InCoB 2019)

Jakarta, Indonesia. 10-12 September 2019

\begin{abstract}
Background: The sensitivity of plants to ammonia is a worldwide problem that limits crop production. Excessive use of ammonium as the sole nitrogen source results in morphological and physiological disorders, and retarded plant growth.

Results: In this study we found that the root growth of Panax notoginseng was inhibited when only adding ammonium nitrogen fertilizer, but the supplement of nitrate fertilizer recovered the integrity, activity and growth of root. Twelve RNA-seq profiles in four sample groups were produced and analyzed to identify deregulated genes in samples with different treatments. In comparisons to $\mathrm{NH}_{4}^{+}$treated samples, $A C L A-3$ gene is up-regulated in samples treated with $\mathrm{NO}_{3}^{-}$and with both $\mathrm{NH}_{4}^{+}$and $\mathrm{NO}_{3}^{-}$, which is further validated by qRT-PCR in another set of samples. Subsequently, we show that the some key metabolites in the TCA cycle are also significantly enhanced when introducing $\mathrm{NO}_{3}^{-}$. These potentially enhance the integrity and recover the growth of Panax notoginseng roots.

Conclusion: These results suggest that the activated TCA cycle, as demonstrated by up-regulation of ACLA-3 and several key metabolites in this cycle, contributes to the increased Panax notoginseng root yield when applying both ammonium and nitrate fertilizer.
\end{abstract}

Keywords: Panax notoginseng, Transcriptome, Nitrate, ACLA-3, Ammonium stress

\section{Background}

Panax notoginseng (Burk.) F. H. Chen (P. notoginseng) belongs to the Araliaceae genus and has been in domesticated cultivation for more than 400 years. P. notoginseng is a famous traditional Chinese medicine for treating

\footnotetext{
*Correspondence: zhengyun5488@gmail.com; yangyekm@163.com; juhuacha2007@sohu.com

${ }^{+}$Xiaohong Ou and Shipeng Li contributed equally to this work.

'Kunming Key Laboratory of Sustainable Development and Utilization of

Famous-Region Drug, Key Laboratory of Panax notoginseng Resources

Sustainable Development and Utilization of State Administration of Traditional

Chinese Medicine, Faculty of Life Science and Technology, Kunming University of Science and Technology, Kunming 650500, China

${ }^{4}$ College of Pharmacy, Hubei University of Chinese Medicine, Wuhan 430065 China

Full list of author information is available at the end of the article
}

cardiovascular and cerebrovascular diseases [1]. According to the statistics of 2016, P. notoginseng has been planted on approximately 53,000 hectares, from which around 50,000 tons of medicinal materials have been harvested, with an agricultural value of up to 1.5 billion dollars. The income from cultivation and processing, as well as from other relevant industries, has become one of the most important economic pillars of Yunnan province. However, since the high values of $P$. notoginseng, abusing nitrogen $(\mathrm{N})$ fertilizers to harvest more raw material is very common $[2,3]$. Abusing $\mathrm{N}$ fertilizers has brought some problems, such as imbalanced of soil nutrients and microbe [3], which could aggravate continuous cropping obstacle [4]. Many studies have been carried out on continuous cropping obstacle till now [5-7]. Furthermore, the

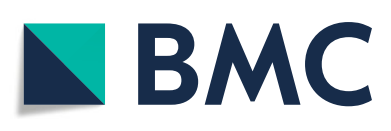

(c) The Author(s). 2019 Open Access This article is distributed under the terms of the Creative Commons Attribution 4.0 International License (http://creativecommons.org/licenses/by/4.0/), which permits unrestricted use, distribution, and reproduction in any medium, provided you give appropriate credit to the original author(s) and the source, provide a link to the Creative Commons license, and indicate if changes were made. The Creative Commons Public Domain Dedication waiver (http://creativecommons.org/publicdomain/zero/1.0/) applies to the data made available in this article, unless otherwise stated. 
average $\mathrm{N}$ application rate in $P$. notoginseng cultivation is approximately $250 \mathrm{~kg} * \mathrm{hm}^{-2}$ [8], causes soil available $\mathrm{N}$ with an average of $213.65 \mathrm{mg} * \mathrm{~kg}^{-1}$ [9], which is $42.4 \%$ higher than the standard of extremely rich level $(\geqslant 150$ $\mathrm{mg} * \mathrm{~kg}^{-1}$ ). Besides, our previous survey shows abusing $\mathrm{N}$ fertilizers causes $\mathrm{NH}_{4}{ }^{+}$concentration of some cultivation soils reaches up to $6 \mathrm{mM}$, which would increase the incidence rate of ammonium toxicity (unpublished data).

Ammonium toxicity is a common phenomenon in agricultural system, and there are a few measures to prevent or alleviate it [10-12]. Among those measures, ammonium and nitrate combined application is thought to be an effective way to prevent ammonium toxicity, but its mechanism is not unified yet [13]. For instance, Roosta et al. [14] suggested that nitrate addition can increase cytokinin synthesis and translocation to alleviate ammonium toxicity of cucumber plants. However, Yang et al. [15] indicated that $A$. thaliana with ammonium and nitrate combined application has a higher auxin content, rather than cytokinin compared to that with ammonium alone. Moreover, nitrate-dependent alleviation of ammonium toxicity in $A$. thaliana is linked to nitrate signaling, uptake and reduction [16], anion channel SLAH3 [13].

With the development of RNA-seq technology, some valuable information can be gained easily by using this technology. Such as, with RNA-seq analysis, Yang et al. [17] have indicated that rice treated with $10 \mathrm{mM}$ ammonium has 63 differentially expressed genes (DEGs) in root and 115 DEGs in leaf compared to that with no ammonium; Sun et al. [18] have reported that rice with $7.5 \mathrm{mM}$ ammonium treated for $4 \mathrm{~h}$ would generate 307 DEGs, involve in carbohydrate, photosynthesis, secondary metabolism, etc., by which the ammonium tolerance of rice can be improved. Moreover, Yang et al. [19] have used RNA-seq to compare the different DEGs of rice with combined treating of ammonium and nitrate and with no $\mathrm{N}$ treating. Similarly, analysis the different DEGs of plants treated with ammonium alone and that with combination of ammonium and nitrate, would get some useful information on nitrate-dependent alleviation of ammonium toxicity, but few reports have reported that till now.

Therefore, based on the ammonium toxicity in P. notoginseng cultivation, the inhibitory of growth phenotypes with $\mathrm{NO}_{3}{ }^{-}$addition were studied by a sandy or hydroponic culture. It showed that the combined application of ammonium and nitrate can alleviate ammonium toxicity of $P$. notoginseng. After that, we identifies thousands of DEGs genes under treatments of different nitrogen forms using RNA-seq. Among up-regulated genes in both nitrate only and nitrate plus ammonium treatments, $A C L A-3$, ATP-citrate lyase $\mathrm{A}-3$, and a few other genes were validated to be up-regulated by qRT-PCR experiments. $A C L A-3$ is the primary enzyme responsible for the synthesis of cytosolic acetyl-CoA in the TCA cycle.
Because of the up-regulation of $A C L A-3$, we examined several metabolites in the TCA cycle, which are also upregulated in both nitrate only and nitrate plus ammonium treatments. These findings are consistent with the activation of TCA cycle when supplying nitrate in other plant species [20]. These results would guide $\mathrm{N}$ fertilization in $P$. notoginseng cultivation, contributes to the recovery of $P$. notoginseng root growth when supplying nitrate to $P$. notoginseng root under ammonium stress.

\section{Results}

\section{Nitrate alleviates the inhibition on root growth of $P$.} notoginseng under ammonium toxicity

At first, we observed the ammonium toxicity phenomenon in a field survey, and then in a sandy culture. To explain the mechanism of the toxicity and to speed up the search procedure, sandy culture and hydroponic culture were used. From the results, we noticed that the phenotypes of the sandy and hydroponic experiments were the same, so we used sandy culture for the experiments to examine physiological status and used hydroponic culture for experiments to examine hair root growth when the plants were treated with different forms of nitrogen fertilizers.

Growth of seedlings with sandy culture was showed in supplementary file (see Additional file 2: Figure S1). We observed that the leaf of CK (without N) was a little chlorosis in the leaf margin, which was caused by $\mathrm{N}$ deficiency. However, leaf of the 15A treatment (with $15 \mathrm{mM}$ $\mathrm{NH}_{4}{ }^{+}$) was totally chlorosis, which was a typical symptom of ammonium toxicity. Both the $15 \mathrm{~N}$ treatment (with $15 \mathrm{mM} \mathrm{NO}_{3}{ }^{-}$) and the $15 \mathrm{AN}$ treatment (with $15 \mathrm{mM}$ $\mathrm{NH}_{4}{ }^{+}+15 \mathrm{mM} \mathrm{NO}_{3}{ }^{-}$) had a green leaf, indicating that seedlings with these two treatments had neither $\mathrm{N}$ deficiency nor ammonium toxicity. The plant height, hair root length, rhizome diameter, root diameter, shoot and root biomass of seedlings were significantly inhibited under $15 \mathrm{~A}$ treatment comparing with those measures in CK (see details in Additional file 2: Figure S2 and Additional file 1: Table S1). Furthermore, the $15 \mathrm{~N}$ treatment had significant promotion effects on the plant height, hair root length, root diameter, shoot and root biomass of seedlings (see details in Additional file 2: Figure S2 and Additional file 1: Table S1). The $15 \mathrm{AN}$ treatment also significantly increased the plant height, hair root length, root biomass of seedlings (see details in Additional file 2: Figure S2). In summary, nitrate recovers the growth of $P$. notoginseng seedlings under $\mathrm{NH}_{4}^{+}$stress.

A hydroponic culture was conducted to test the effects of different nitrogen forms on hair root growth of $P$. notoginseng seedlings (Fig. 1). E-B staining analysis of root tips showed that plasma membrane of root tip cells was gradually damaged with the nitrogen concentration increasing, because the degree of blue color represents the degree 


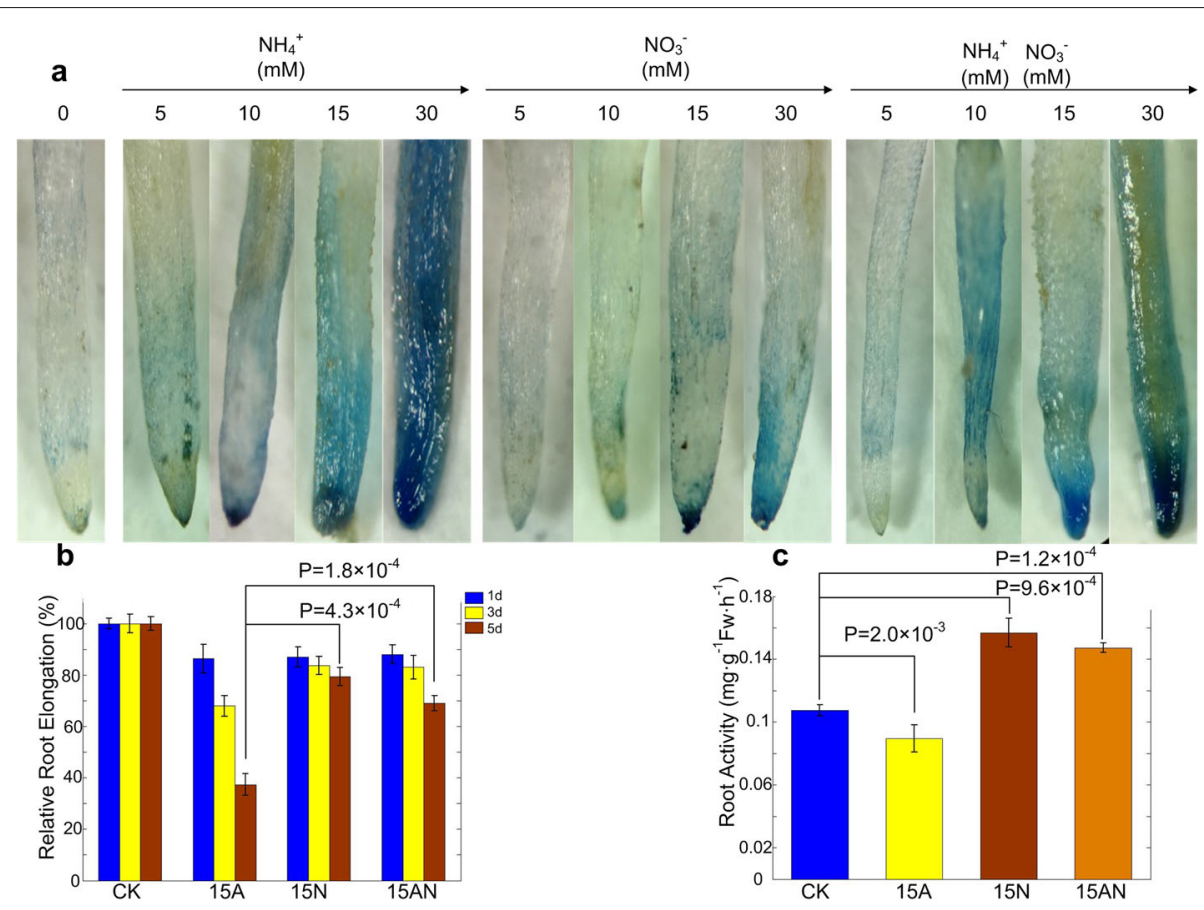

Fig. 1 Effects of different forms of nitrogen treatments with different concentration gradients on root tips of $P$. notoginseng. a The plasma membrane integrity of root tips of $P$. notoginseng under different treatment conditions, Numbers represent different concentration gradients. $\mathbf{b}$ The Relative Root Elongation of root tips of P. notoginseng under different forms of nitrogen treatments. The $1 \mathrm{~d}, 3 \mathrm{~d}$, and $5 \mathrm{~d}$ represent the first day, the third day, and the fifth day, respectively. c The Root Activity of $P$. notoginseng Effect under different forms of nitrogen treatments

of root damage. The damage degree caused by ammonium treatment was the most serious, the second one was the sample treated with ammonium combined nitrate, and minor effects were observed under nitrate treatments (Fig. 1a). The relative root elongation (RRE) under 15A treatment was approximately $37 \%$, which was significantly lower than that under $15 \mathrm{~N}$ and $15 \mathrm{AN}$ treatments $(P=$ $4.3 \times 10^{-4}$ and $P=1.8 \times 10^{-4}$, respectively, Student's $t$ test), respectively, after five days (Fig. $1 \mathrm{~b}$ and Additional file 1: Table S2). Meanwhile, the root activity of $15 \mathrm{~A}$ treatment was significantly lower than that of CK $(P=2.0 \times$ $10^{-3}$, Student's $t$-test), and significantly lower than those under the $15 \mathrm{~N}$ and $15 \mathrm{AN}$ treatments $\left(P=2.5 \times 10^{-4}\right.$ and $P=2.7 \times 10^{-5}$, respectively, Student's $t$-test), respectively (Fig. 1c and Additional file 1: Table S3). All results above indicated that $P$. notoginseng seedlings treated with ammonium had a visible toxicity effects, i.e., root tip damage, root elongation and growth inhibition, as well as low biomass, and nitrate could alleviate the toxicity symptom caused by ammonium.

\section{RNA-Seq profiles of $P$. notoginseng roots under different forms of nitrogen treatments}

According to results of E-B staining analysis for plasma membrane of $P$. notoginseng root tips, we hypothesized that $15 \mathrm{~A}, 15 \mathrm{~N}$, and $15 \mathrm{AN}$ treatments could significantly affect the metabolism of $P$. notoginseng, without producing significant damage. Therefore, transcriptome analysis of $P$. notoginseng roots were performed under the treatments with $15 \mathrm{mM}$ for each condition (Fig. 1a).

We generated 12 RNA-seq libraries from the pooled RNA samples isolated from $P$. notoginseng roots, with 3 samples for CK, $15 \mathrm{~A}, 15 \mathrm{~N}$, and $15 \mathrm{AN}$, respectively. Plants were grown under greenhouse conditions without special treatments. These 12 RNA-seq libraries were sequenced using Illumina HiSeq 2000 sequencer, and approximately 20 million reads were obtained for each of the libraries. After examining the scores per nucleotides with FASTQC, the qualities of the obtained RNA-seq sequencing profiles were generally good with scores (see Additional file 2: Figure S3).

\section{P. notoginseng roots under the same treatments have similar gene expression profiles}

The obtained sequencing data were aligned to the $P$. notoginseng genome [21] and assembled with the Cufflinks pipeline [22] (see details in Materials and methods). We obtained approximately $95 \%$ mapped rate to the reference genome [21] (see details in Additional file 1: Table S4).

We totally obtained 146,330 assembled genes of which 138,976 overlapped to annotated genes reported previously [21] (Additional file 2: Figure S4a) and 7354 were novel and did not overlap to previously annotated genes (Additional file 2: Figure S4a), suggesting the annotation 
of the reported genome is incomplete. Our assembly of transcript did not cover 1764 genes reported previously. The average abundances of the assembled genes were between 10 to 100 FPKM (Additional file 2: Figure S4b). The average expression levels of most genes are smaller than 500 FPKM in all four experimental groups (Additional file 2: Figure S4c to S4f).

The genes with average abundances and variances of abundances of at least 5 FPKM (Additional file 1: Table S5) were selected to perform Principle Component Analysis (PCA) and Hierarchical Clustering. The samples from the same treatments were clustered together and samples from different treatments were clearly differentiated (Fig. 2a). We also found the strong correlation among the samples of the same treatment, meanwhile samples from different processing conditions have much lower correlation coefficient values (Fig. 2b). These results suggest that samples in the sample groups have similar gene expression patterns and a good repeatability of the RNA-seq profiles.

\section{Differentially expressed genes in different forms of nitrogen treatments in $P$. notoginseng roots}

In order to explore the mechanisms by which the toxicity of ammonium was reduced after nitrate treatments, we identified differentially expressed genes (DEGs) in different treatments when compared to control using the edgeR package [23] (see details in Material and methods). The significantly differently expressed genes were identified with False Discovery Rate (FDR) values of $<0.05$ and absolute log-scaled fold change $\left(\left|\log _{2} \mathrm{FC}\right|\right)>1$ (Additional file 1: Table S6 to S11). The numbers of DEGs were shown in Fig. 2c and d.

According to the results of physiological experiments, we noticed that nitrate could alleviate ammonium toxicity. Thus, we selected 117 up-regulated and 268 downregulated genes under $15 \mathrm{~N}$ and $15 \mathrm{AN}$ treatments but not under $15 \mathrm{~A}$ treatment to perform a Biclustering analysis (Fig. 2e). The results show that the sample of different groups were correctly clustered, suggesting these genes contribute to the differences in different groups.

\section{Functional analysis of differentially expressed genes}

DEGs in different treatments were used to identify enriched Gene Ontology (GO) terms (Additional file 1: Table S12 to Table S17) and KEGG pathways (Additional file 1: Table S20 to Table S25). Similarly, the number of enriched GO terms and KEGG pathways enriched in DEGs were shown under different treatments (see details in Additional file 2: Figure S5 and Materials and methods).
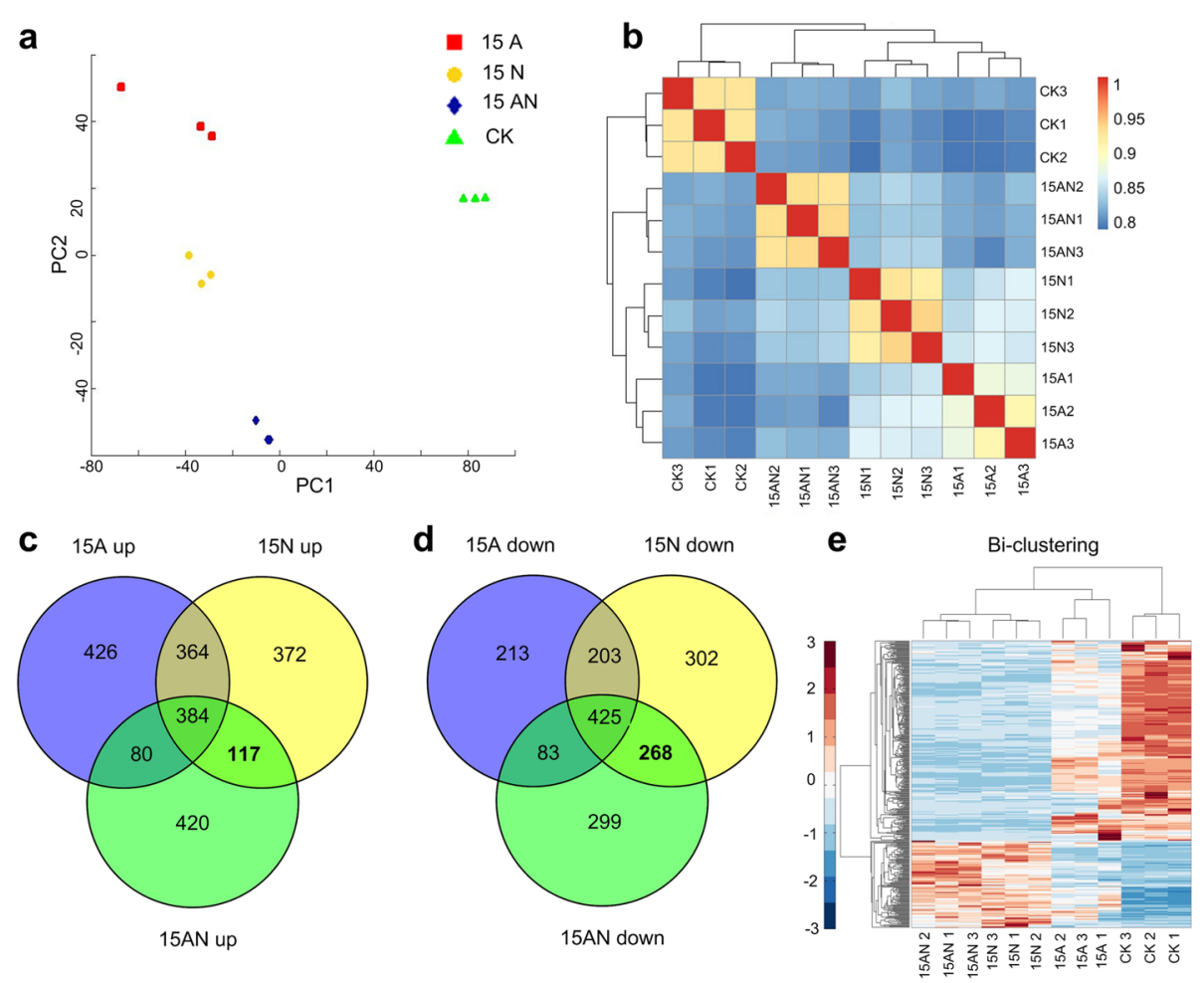

Fig. 2 Differentially expressed genes in different forms of nitrogen treatments in P. notoginseng. $\mathbf{a}$ The PCA analysis of RNA-Seq expression profiles in different treatment conditions. b The hierarchical clustering of RNA-Seq expression profiles in different conditions. $\mathbf{c}$ and $\mathbf{d}$ The number of up-regulated genes and down-regulated identified under different conditions in this study, respectively. $\mathbf{e}$ The up-regulated and down-regulated genes bi-clustering of RNA-Seq expression profiles in different treatment conditions 
The common GO terms in up-regulated DEGs in $15 \mathrm{~N}$ and $15 \mathrm{AN}$ but not in $15 \mathrm{~A}$ include vacuolar membrane (GO:0005774), vacuolar part (GO:0044437), cofactor metabolic process (GO:0051186), cellular response to water deprivation (GO:0042631), cellular response to abiotic stimulus (GO:0071214) and so on (Additional file 1: Table S18 and Additional file 2: Figure S5a).

Similarly, the common GO terms of the down-regulated DEGs in $15 \mathrm{~N}$ and $15 \mathrm{AN}$ but not in 15A include photosynthesis, light reaction (GO:0019684), photosynthesis, light harvesting in photosystem I (GO:0009768), generation of precursor metabolites and energy (GO:0006091), carbohydrate metabolic process (GO:0005975), sucrose metabolic process (GO:0005985), amino acid catabolic processes (GO:0009065, GO:0009068, GO:1901606), nitrogen transport (GO:0015706), and carbon metabolism processes (GO:0015977, GO:0005975). Among the cellular components category, significant GO terms include photosystem I (GO:0009522), chloroplast thylakoid membrane plastid (GO:0009535), thylakoid membrane (GO:0055035), and so on. For the molecular function, significant $\mathrm{GO}$ terms include pigment binding (GO:0031409) and nitrate transmembrane transporter activity (GO:0015112) which was involved in nitrogen metabolism (Additional file 1: Table S19 and Additional file 2: Figure S5c).

Meanwhile, the common KEGG pathways in $15 \mathrm{~N}$ and $15 \mathrm{AN}$ but not in 15A are TCA cycle (ath00020), Plant hormone signal transduction (ath04075), and Taurine and hypotaurine metabolism (ath00430) for up-regulated genes (see details in Table 1 and Additional file 2: Figure $\mathrm{S} 5 \mathrm{~b}$ ). In down-regulated genes, the common KEGG pathways in $15 \mathrm{~N}$ and $15 \mathrm{AN}$ but not in $15 \mathrm{~A}$ are Photosynthesis (ath00195), Glutathione metabolism (ath00480), Amino sugar and nucleotide sugar metabolism (ath00520), Starch and sucrose metabolism (ath00500), and Porphyrin and chlorophyll metabolism (ath00860) (see details in Table 1 and Additional file 2: Figure S5d).

Because the supplements of nitrate alleviate the ammonium toxicity, we examined the 117 and 268 up- and down-regulated genes that are shared in the $15 \mathrm{~N}$ and $15 \mathrm{AN}$ treated groups and not in $15 \mathrm{~A}$ treated group, and analyzed the enriched GO and KEGG pathways of these genes (as shown in Fig. 3). ACLA-3 is one of the commonly up-regulated genes and appears in many significant common GO terms and KEGG pathways of $15 \mathrm{~N}$ and $15 \mathrm{AN}$ treated groups (see Fig. 3a). Therefore, we choose to further validate its expression. Furthermore, the common up-regulated genes of $15 \mathrm{~N}$ and $15 \mathrm{AN}$ treated groups are enriched in the TCA cycle (Additional file 1: Table S26), in which $A C L A-3$ is also involved.

As shown Fig. 3b, the 268 down-regulated genes are enriched in many GO terms related to photosynthesis, which was consistent with the common GO terms in $15 \mathrm{~N}$ and $15 \mathrm{AN}$ but not in $15 \mathrm{~A}$ (Additional file 1 : Table S19).

\section{Validation of the expression of DEGs that may contribute to the alleviated ammonium toxicity}

To verify the expression of several key DEGs that may contribute to alleviated ammonium toxicity, we performed quantitative RT-PCR (qRT-PCR) assays with independent samples collected from the $P$. notoginseng roots under different treatments (CK, 15A, 15N, and 15AN). We selected 10 genes that are commonly deregulated in $15 \mathrm{~N}$ and $15 \mathrm{AN}$ treatments but not in 15A, i.e., 6 up-regulated and 4 down-regulated ones, identified in the RNA-Seq data (Fig. 4a and b, Additional file 2: Figure S6a to S6d, Additional file 1: Table S29 and Table S32), which potentially alleviate ammonium toxicity.

The qRT-PCR results show that four of the six commonly deregulated genes in $15 \mathrm{~N}$ and $15 \mathrm{AN}$, i.e., an $\mathrm{ABC}$ transporter, a coiled-coil protein, an unknown gene (XLOC_035411), and ACLA-3, show up-regulated expression levels in $15 \mathrm{~N}$ and $15 \mathrm{AN}$ when compared to $15 \mathrm{~A}$ using qRT-PCR experiments (Fig. 4c and Additional file 1: Table S29), which is the same as those in RNA-seq profiles. $\mathrm{ADH}$, commonly up-regulated in $15 \mathrm{~A}, 15 \mathrm{~N}$ and $15 \mathrm{AN}$ treatments, also has up-regulated expression levels in $15 \mathrm{~N}$ and $15 \mathrm{AN}$ in the qRT-PCR experiments. The

Table 1 KEGG pathways of common DEGs between 15N and 15AN

\begin{tabular}{|c|c|c|c|c|c|c|c|c|}
\hline & \multirow{2}{*}{ KEGG pathway } & \multirow{2}{*}{ ID } & \multicolumn{3}{|l|}{$15 N$} & \multicolumn{3}{|l|}{$15 \mathrm{AN}$} \\
\hline & & & Input & Total & $P$-Value & Input & Total & P-Value \\
\hline \multirow[t]{3}{*}{ Up-regulated DEGs } & Citrate cycle (TCA cycle) & ath00020 & 6 & 63 & $1.18 \mathrm{E}-2$ & 7 & 63 & $5.32 \mathrm{E}-4$ \\
\hline & Taurine and hypotaurine metabolism & ath00430 & 3 & 14 & $1.06 \mathrm{E}-2$ & 3 & 14 & $4.53 \mathrm{E}-3$ \\
\hline & Plant hormone signal transduction & ath04075 & 17 & 271 & $2.79 \mathrm{E}-3$ & 12 & 271 & $1.32 \mathrm{E}-2$ \\
\hline \multirow[t]{5}{*}{ Down-regulated DEGs } & Photosynthesis & ath00195 & 12 & 77 & $1.26 \mathrm{E}-5$ & 10 & 77 & $9.74 \mathrm{E}-5$ \\
\hline & Glutathione metabolism & ath00480 & 8 & 93 & $1.04 \mathrm{E}-2$ & 7 & 93 & $1.66 \mathrm{E}-2$ \\
\hline & Starch and sucrose metabolism & ath00500 & 13 & 202 & $1.24 \mathrm{E}-2$ & 11 & 202 & $2.63 \mathrm{E}-2$ \\
\hline & Amino sugar and nucleotide sugar metabolism & ath00520 & 10 & 135 & 1.15E-2 & 9 & 135 & $1.43 \mathrm{E}-2$ \\
\hline & Porphyrin and chlorophyll metabolism & ath00860 & 5 & 48 & $2.02 \mathrm{E}-2$ & 4 & 48 & $4.78 \mathrm{E}-2$ \\
\hline
\end{tabular}



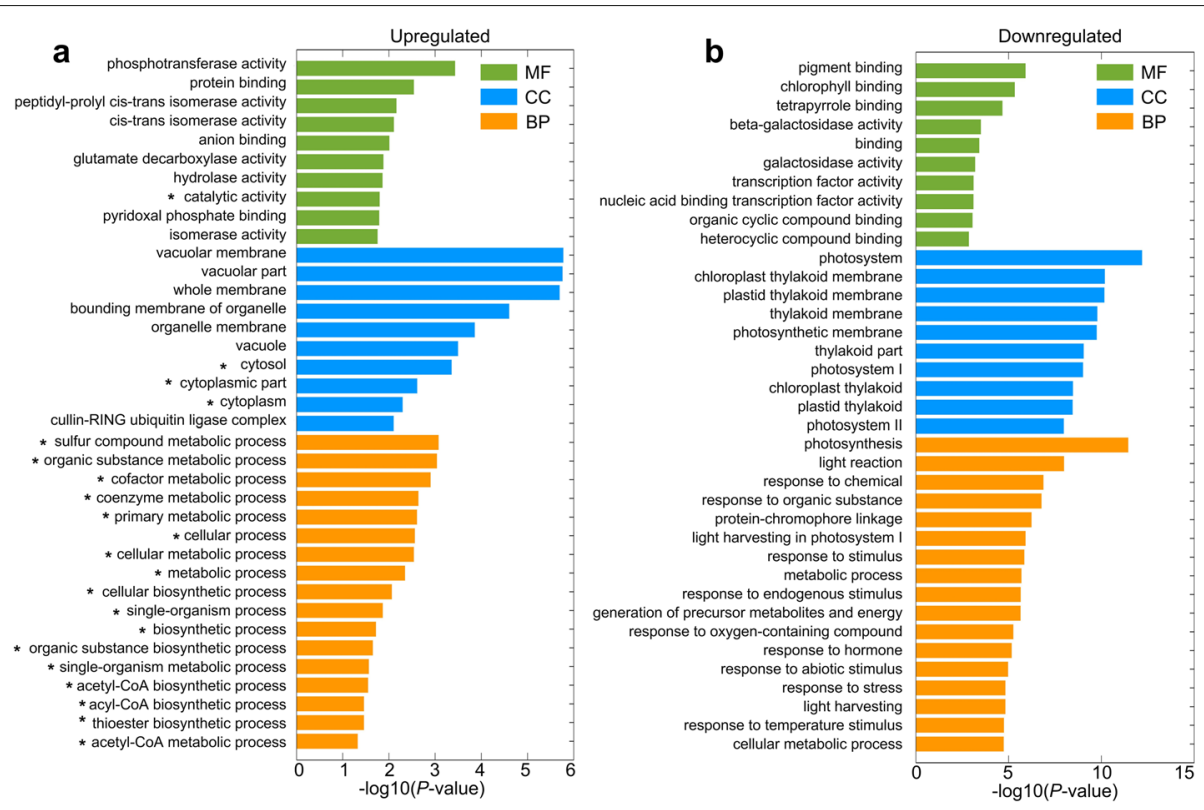

Fig. 3 Enriched GO terms for the commonly deregulated genes in $15 \mathrm{~N}$ and $15 \mathrm{AN}$ treatments but not in $15 \mathrm{~A}$ treatment. a The enriched $\mathrm{GO}$ terms of 117 up-regulated genes. The asterisk represents the pathway in which ACLA-3 is involved. $\mathbf{b}$ The enriched GO terms of 268 down-regulated genes

expression of three of the four down-regulated genes, i.e., an unknown gene (XLOC_109320), DRM1/ARP, and ACIK1, in $15 \mathrm{~N}$ and $15 \mathrm{AN}$ treatments were validated using qRT-PCR (Fig. 4d, Additional file 2: Figure S6d, and Additional file 1: Table S29). It should be noticed that the $P$. notoginseng plants used in qRT-PCR experiments were not the same as those used in RNA-seq profiling. Therefore there could be small discrepancy between the expression levels obtained in qRT-PCR experiments and those in RNA-seq profiles, such as those of ADH.

We also selected 9 and 6 genes that are commonly upand down-regulated in $15 \mathrm{~A}, 15 \mathrm{~N}$ and $15 \mathrm{AN}$ treatments for verification using qRT-PCR (Additional file 1: Table S32). The qRT-PCR results show that the expression levels of these genes have no unified patterns (Additional file 2: Figure S6). After performing GO and KEGG pathway analysis for the 384 and 425 commonly up- and downregulated genes in $15 \mathrm{~A}, 15 \mathrm{~N}$ and $15 \mathrm{AN}$ treatments, we found that the up-regulated genes are mainly enriched in various metabolic processes, including oxidoreductase activity, acting on paired donors, with oxidation of a pair of donors resulting in the reduction of molecular oxygen to two molecules of water (GO:0016717); unsaturated fatty acid biosynthetic process (GO:0006636); and unsaturated fatty acid metabolic process (GO:0033559). The enriched KEGG pathways of up-regulated genes include Biosynthesis of unsaturated fatty acids (ath01040) and Fatty acid metabolism (ath01212). And down-regulated genes are mainly involved in response to stresses, including response to stimulus (GO:0050896); response to chemical (GO:0042221); response to organic substance (GO:0010033). The enriched KEGG pathways of downregulated genes include Metabolic pathways (ath01100) and Biosynthesis of secondary metabolites (ath01110). These results suggest that these genes probably contribute to the general stress responses and metabolic processes.

\section{Validation on metabolites involved in the alleviation pathway of $A C L A-3$}

Previous studies have demonstrated an imbalance of carbon and nitrogen metabolism is an important mechanism for ammonium toxicity [24-26]. By using RNA-seq analysis, this study showed the gene, $A C L A-3$, played an important role in the TCA cycle, which could involve in the alleviation pathway of ammonium toxicity by regulating the carbon and nitrogen metabolism of $P$. notoginseng. Thus, this study determined the metabolites contents and enzymes activities, which might relate to the pathway involving the gene of $A C L A-3$. Compared to $C K$, the $15 \mathrm{~A}$ treatment significantly increased the accumulation of free $\mathrm{NH}_{4}{ }^{+}$, which is mainly reason for imbalance carbon and nitrogen metabolism [24-26], however, the accumulation could be significantly decreased with the 15AN treatment (Fig. 5a). Moreover, compared to CK, the 15A treatment significantly decreased the content of organic acids (malate, citrate, succinate and fumarate, Fig. 5b) and carbohydrates (soluble sugar, glucose, sucrose and starch, Fig. 5c), as well as the activity of MDH, ICDH and PEPC of the TCA cycle (Fig. $5 \mathrm{~d}$ ), but all of those could be increased 

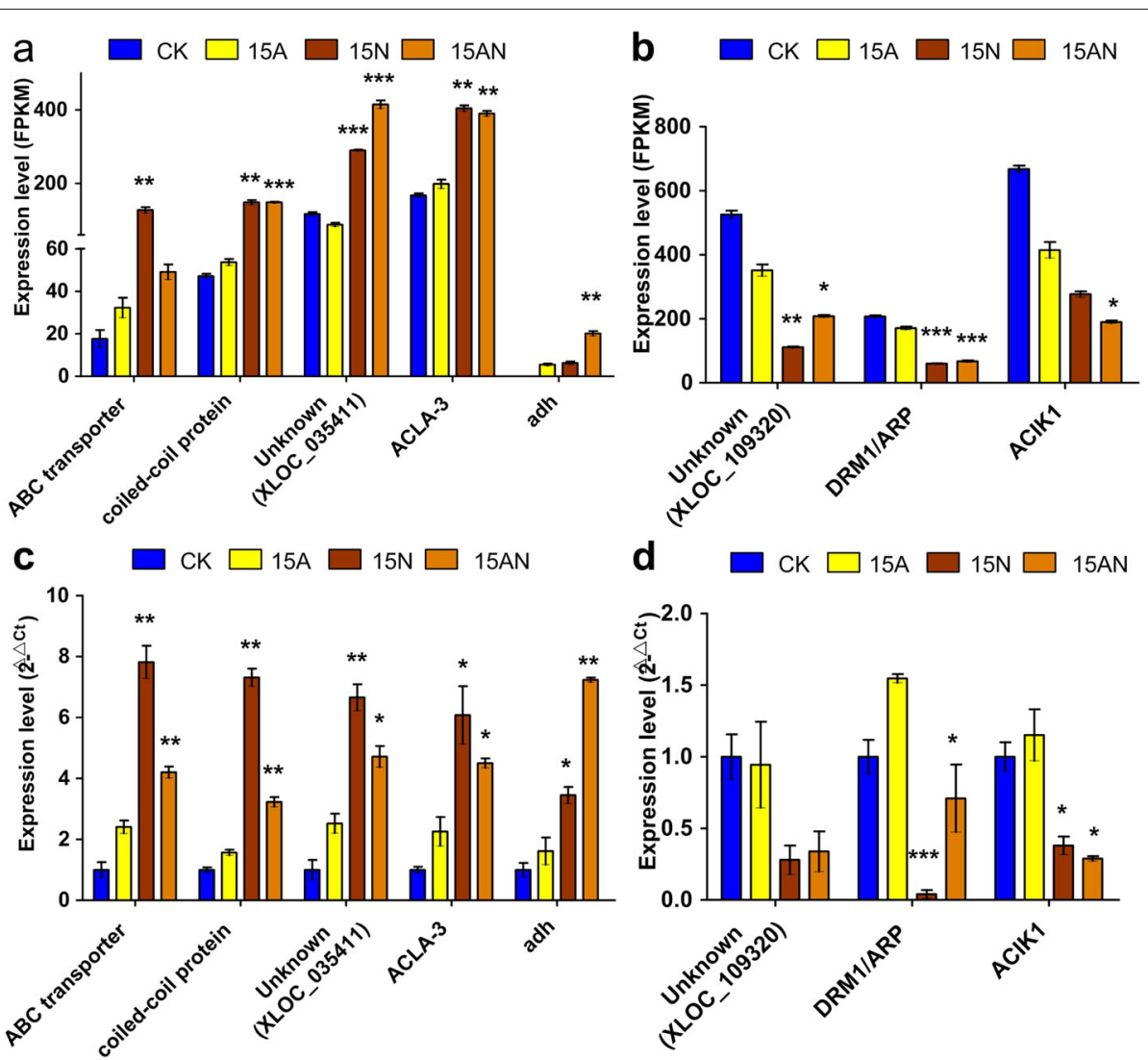

Fig. 4 Validating expression patterns of up- or down-regulated genes in the $15 \mathrm{~N}$ and $15 \mathrm{AN}$ treatments but not in $15 \mathrm{~A}$ treatment by qRT-PCR in $P$. notoginseng. All values shown are mean values \pm standard errors (S.E.). The asterisks indicate significant differences compared with the $15 \mathrm{~A}$ treatment under the same treatment conditions (Student's $t$-test). Standard deviations were calculated from three technical replicates. The results shown were reproduced with three biological replicates. ${ }^{*}$ represents $P$-values $<0.05$; ${ }^{* *}$ represents $P$-values $<0.01$; ${ }^{* * *}$ represents $P$-values $<0.001$. a and $\mathbf{b}$ The up- and down-regulated genes in the $15 \mathrm{~N}$ and $15 \mathrm{AN}$ treatments detected using RNA-seq profiles in $P$. notoginseng. (c) and (d) The expression levels of the up- and down-regulated genes in Part (a) and (b), respectively, verified using qRT-PCR

with the 15AN treatment (see more details in Additional file 1: Table S30 and S31, respectively). Among of the contents of main amino acid, Gln and Thr have decreased contents in $15 \mathrm{~N}$ treatment when compared to $15 \mathrm{~A}$; Arg has a decreased content in $15 \mathrm{AN}$ treatment when compared to 15A (Additional 2: Figure S7). Thus, these results suggested that $A L C A-3$ is involved in nitratedependent alleviation of ammonium toxicity by regulating related carbon metabolism.

\section{Discussion}

Nitrate alleviates the inhibitory effect of ammonium on the plant growth

Ammonium toxicity can inhibit the root growth, then restrain the development of aboveground, subsequently reduce crop production and may even result in death [10, 27]. Hoopen et al. [28] indicated that barley seedlings $(H$. vulgare) treated for 3 days with nutrition solution containing $1.5 \mathrm{mM} \mathrm{NO}_{3}{ }^{-}$, then transplanted to a complete nutrition solution containing 3 or $6 \mathrm{mM} \mathrm{NH}_{4}^{+}$for 5 days, the fresh root weight is decreased by $28 \%-32 \%$, comparing with that treated with $1.5 \mathrm{mM} \mathrm{NO}_{3}{ }^{-}$. Li et al. [29] found that only the root tip or whole root of $A$. thaliana in contact with $\mathrm{NH}_{4}{ }^{+}$containing medium can inhibit the root elongation. Liu et al. [30] found that the root tip cell length and division are evidently decreased in the meristem zone of $A$. thaliana when supplied with ammonium. Thus, the root specifically the root tip is the primary part that sensitive to ammonium toxicity. The present study suggested that $P$. notoginseng seedlings treated with ammonium alone can inhibit the growth and biomass accumulation obviously (Additional file 1: Table S1, S2, and S3, Fig. 1a, Additional file 2: Figure S1, S2). Furthermore, the root elongation and root activity of $P$. notoginseng seedlings are significantly inhibited by the increasing concentration of ammonium, and root plasma membrane also is severely damaged (Fig. 1b). However, addition of $\mathrm{NO}_{3}{ }^{-}$can alleviate the inhibitory effect caused by ammonium (Fig. 1, Additional file 2: Figure S1, S2). These results are similar to that of Yang et al. [15], who 

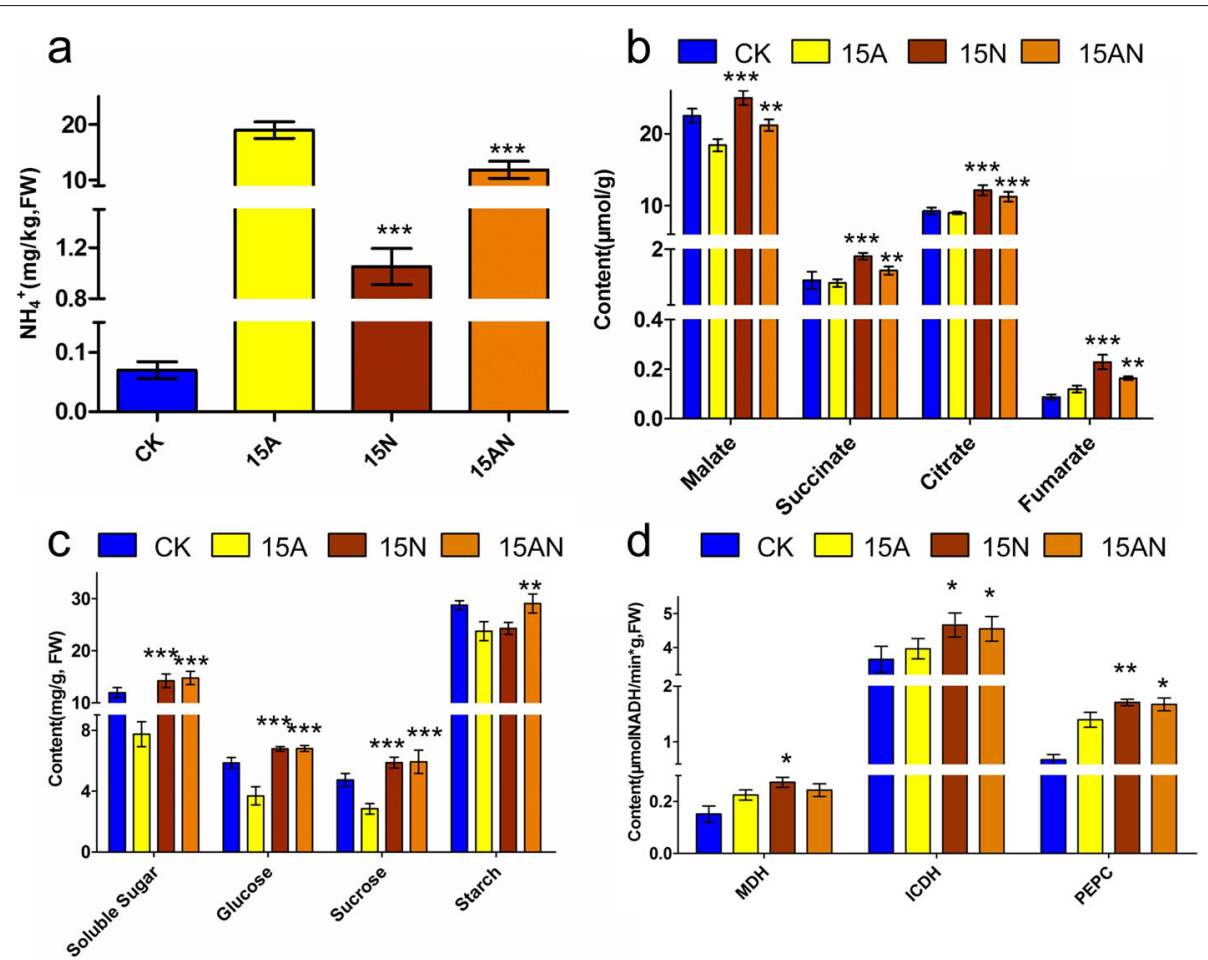

Fig. 5 The contents of some metabolites associated with TCA metabolic pathway in P. notoginseng roots under different forms of nitrogen treatments. All values shown are mean values \pm standard errors (S.E.). The asterisks indicate significant differences compared with the $15 \mathrm{~A}$ treatment under the same treatment conditions (Student's $t$-test). Standard deviations were calculated from three technical replicates. The results shown were reproduced with three biological replicates. ${ }^{*}$ represents $P$-values $<0.05$; ${ }^{* *}$ represents $P$-values $<0.01$; ${ }^{* * *}$ represents $P$-values $<0.001$. a Effects of the different forms of nitrogen treatments on changes of organic acids in TCA cycle of $P$. notoginseng. $\mathbf{b}$ The changes of organic acid synthases in TCA cycle. $\mathbf{c}$ The changes of major sugar compounds in TCA cycle. $\mathbf{d}$ The $\mathrm{NH}_{4}{ }^{+}$content in TCA cycle

found that $A$. thaliana seedlings treated with $\mathrm{NH}_{4} \mathrm{NO}_{3}$ as $\mathrm{N}$ source had an approximately 10-fold longer root length compared to that treated with $\mathrm{NH}_{4}{ }^{+}$as $\mathrm{N}$ source. Consequently, it is suggested that $\mathrm{NO}_{3}{ }^{-}$can alleviate ammonium toxicity effects on the growth of $P$. notoginseng seedlings.

\section{The unbalanced metabolism of carbon and nitrogen caused by $\mathrm{NH}_{4}{ }^{+}$is one of the causes of poisoning to $P$. notoginseng roots}

It is widely accepted that $\mathrm{NH}_{4}{ }^{+}$assimilated primarily into organic compounds via glutamine synthetase/glutamate synthase pathway (GS/GOGAT; GS, EC 6.3.1.2; GOGAT, EC 1.4.1.14) [31], which catalyzes $\mathrm{NH}_{4}{ }^{+}$and $\alpha$ ketoglutarate to synthesize glutamate. In regular growing, the carbon/nitrogen metabolism of plant is in equilibrium. The $\mathrm{NH}_{4}{ }^{+}$absorbed by plants needs to be converted into amino acids by $\alpha$-ketoglutarate as a carbon frame under the action of $\mathrm{NH}_{4}{ }^{+}$assimilation enzymes, and then converted into protein by plants.

However, the plant absorbs $\mathrm{NH}_{4}{ }^{+}$, will consume a lot $\alpha$-ketoglutarate. When the plant itself is low carbohydrate content, or when the amount of carbohydrates converted to $\alpha$-ketoglutarate by the TCA cycle is insufficient for $\mathrm{NH}_{4}{ }^{+}$assimilation, it will cause an unbalance in the carbon and nitrogen metabolism of the plants, which in turn will cause poisoning to the plants. For example, Ariz et al. [26] study found that increased $\mathrm{NH}_{4}{ }^{+}$ concentration results in reduced Pisum sativum Linn carbohydrate content as a cause of ammonium toxicity. Vega-Mas et al. [32] also considered that the cause of ammonium toxicity in tomato is that the large amount of $\mathrm{NH}_{4}{ }^{+}$assimilation leads to imbalance of its carbon and nitrogen metabolism. When exposed to ammonium stress, plants will initiate their own defense mechanisms to reduce the impact of ammonium stress on carbon and nitrogen metabolism imbalance. In that equilibrium, $\alpha$ ketoglutarate in plant which is a intermediate product of TCA cycle, is enough for $\mathrm{NH}_{4}{ }^{+}$assimilation. Wherein, PEPC, MDH and ICDH are the key enzymes affecting the production of $\alpha$-ketoglutarate during the TCA cycle $[33,34]$.

Interestingly, there is a widely consensus that elevating carbohydrate content can increase the organic acids synthetases activity of TCA cycle to alleviate ammonium toxicity. For instance, addition exogenous $C$ can increase PEPC activity [35]; high irradiance improves carbohydrate content and organic acids synthetases 
activity [36]; elevated $\mathrm{CO}_{2}$ increases carbohydrate content and removes the inhibition of ammonium toxicity on organic acids synthetases activity [32, 37]. In addition, Setié et al. [38] indicated that tomato seedlings (Agora Hybrid F1) treated with $10 \mathrm{mM}$ nitrate solution have higher $\alpha$-ketoglutarate content than that treated with 10 $\mathrm{mM}$ ammonium solution. As shown above, our results indicate that $\mathrm{NO}_{3}{ }^{-}$can up-regulate ACLA-3 and other compounds in the TCA cycle (Fig. 5a and 6), which subsequently increases the activity of organic acids synthetases (Fig. 5b), contents of carbohydrates (Fig. 5c). These potentially will increase the content of $\alpha$-ketoglutarate for accelerating $\mathrm{NH}_{4}{ }^{+}$assimilation. Our results indicate that the content of $\mathrm{NH}_{4}{ }^{+}$was significantly decreased when adding nitrate, as shown in Fig. 5d.

Nitrate alleviates ammonium toxicity by enhancing $A C L A-3$ The imbalance of carbon and nitrogen metabolism is an important mechanism for ammonium toxicity [26]. On the one hand, the imbalance is due to excessive free $\mathrm{NH}_{4}{ }^{+}$ accumulation in plants, which needs massive carbohydrates to assimilated it $[39,40]$. On the other hand, the imbalance is due to the reducing of carbohydrate accumulation, which is caused by inhibiting photosynthesis [41]. In view of this, decreasing the accumulation of $\mathrm{NH}_{4}{ }^{+}$or increasing the accumulation of carbohydrate is considered to be an effective way for ammonium toxicity alleviation. Studies have indicated that exogenous addition of $\mathrm{CO}_{3}{ }^{2-}$ [14], $\mathrm{HCO}_{3}{ }^{-}$[42], glucose [43] or increasing irradiance [36] or $\mathrm{CO}_{2}[32,37]$ can improve the carbohydrate accumulation to alleviate ammonium toxicity by balancing carbon and nitrogen metabolism. Interestingly, all of these measures are related to the TCA cycle, which can provide $\alpha$-ketoglutarate, a primary carbon skeleton for $\mathrm{NH}_{4}{ }^{+}$ assimilation. For instance, Roosta et al. [14] have demonstrated addition $\mathrm{CO}_{3}{ }^{2-}$ can improve the PEPC activity of cucumber seedlings under ammonium toxicity. Vega-Mas et al. [37] showed that increasing the ambient $\mathrm{CO}_{2}$ concentration also improves the synthase activity in the TCA cycle of tomato plants under ammonium stress. Thus, the TCA cycle has a significance in the alleviation of ammonium toxicity.

Based on the results of RNA-seq, we found P. notoginseng roots in $15 \mathrm{~N}$ and $15 \mathrm{AN}$ treatments have 117 and 268 common up- and down-regulated genes, respectively (Fig. 2c, d). Then the expression pattern of 5 and 3 significantly up- and down-regulated genes were confirmed using qRT-PCR, respectively (Fig. 4c to d, Additional file 1: Table S28, S29 and S32). These results show the expression of $A C L A-3$ (XLOC-057761) is significantly upregulated (Figure 6) in both $15 \mathrm{~N}$ and $15 \mathrm{AN}$ treatments when compared to $15 \mathrm{~A}$ treatment. This gene is homologous with ACLA-3 (AT1G09430) of A. thaliana, mainly participate in modulating TCA cycle [44, 45]. Our results also indicated that several key metabolites, i.e., citrate, succinate, fumarate, and malate, in the TCA cycle are also significantly enhanced in both $15 \mathrm{~N}$ and $15 \mathrm{AN}$ treatments (Fig. 6). These results suggest that nitrate addition can activate TCA cycle by up-regulating $A C L A-3$ to synthesize more $\alpha$-ketoglutarate for accelerating $\mathrm{NH}_{4}{ }^{+}$assimilation, and alleviate the ammonium toxicity (Fig. 6), which is also noticed in other species [20]. Thus, the activation of TCA cycle represents a conserved mechanism for the recovery of plant growth when adding nitrate to plants under ammonium stress.

As reported previously, ammonium toxicity causes an imbalance of carbon/nitrogen metabolism [39, 40]. Therefore, maintaining carbon/nitrogen metabolism balance can effectively avoid ammonium toxicity, which means to reduce the uptake of $\mathrm{NH}_{4}{ }^{+}$or to increase $\alpha$-ketoglutarate content. Several researches indicated that addition $\mathrm{NO}_{3}{ }^{-}$ $[10,46]$ can reduce the uptake of $\mathrm{NH}_{4}^{+}$to alleviate ammonium toxicity. Hachiya et al. [47] further supported the idea of $\mathrm{NO}_{3}{ }^{-}$addition can up-regulated the expression of genes that related to nitrate signal in $A$. thaliana. Moreover, Yang et al. [15] showed ammonium and nitrate combination can increase auxin content to alleviate ammonium toxicity of A. thaliana; Zheng et al.

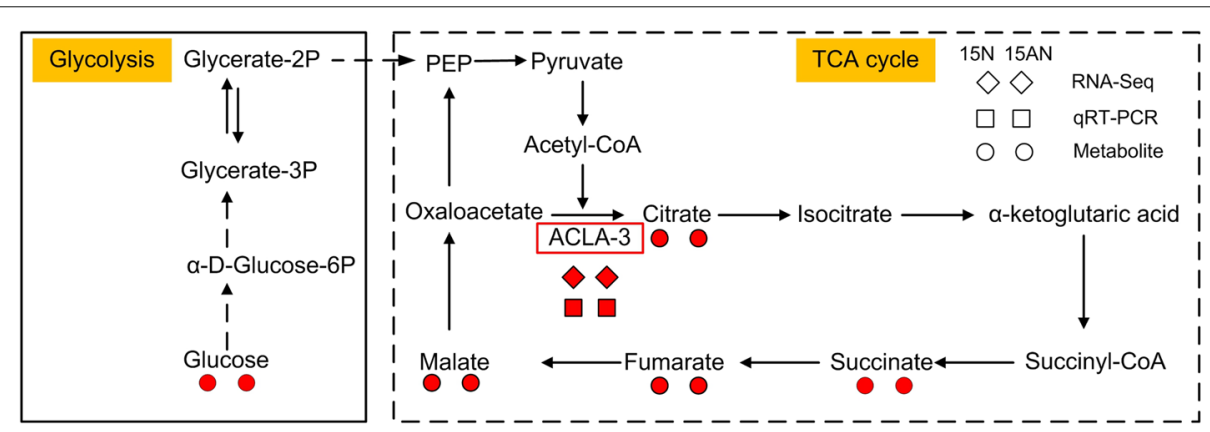

Fig. 6 Schematic representation of glycolysis and TCA cycle in P. notoginseng. Solid arrows represent direct procedures. Dashed arrows represent indirect procedures. The red squares and red diamonds below the $A C L A-3$ gene in the red rectangle mean that $A C L A-3$ is up-regulated in $15 \mathrm{~N}$ and $15 \mathrm{AN}$ treatments but not in 15A treatment as validated with qRT-PCR and RNA-seq, respectively. Red circles represent up-regulated metabolites 
[13] found $\mathrm{NO}_{3}{ }^{-}$addition can regulate slow anion channels genes (SLAH3) to alleviate ammonium toxicity of $A$. thaliana. Our results show that addition of $\mathrm{NO}_{3}{ }^{-}$can alleviate ammonium toxicity in $P$. notoginseng root potentially by activating $A C L A-3$ and the TCA cycle, as reported in other species [20]. To summarize, the alleviation of ammonium toxicity when adding nitrate might be realized through multiple mechanisms.

An $\mathrm{ABC}$ transporter gene and a coiled-coil protein gene were also verified to have increased abundances in both $15 \mathrm{~N}$ and 15AN treatments (Fig. 4a and c). $\mathrm{ABC}$ transporter is involves in the transportation of a large variety of nutrients, biosynthetic precursors, trace metals and vitamins, which is essential for the normal growth of plants [48-52]. Thus, the enhanced ABC transporter gene potentially contribute to the recovered growth when adding nitrates. The coiled-coil protein genes often involved in gene regulation whose relation to the relieved toxicity when adding nitrate will need more studies. Among the confirmed down-regulated genes in both $15 \mathrm{~N}$ and 15AN treatments, DRM1/ARP (dormancy-associated gene-1/auxin-repressed protein) is a marker for dormancy release and expressed in tissues other than dormant axillary buds with high expression often localized to nongrowing tissues [53]. Our results suggest that DRM1/ARP is repressed when adding nitrate to recover normal tissue growth (Fig. 4b and d). ACIK1 is serine/threonine-protein kinase At5g01020-like, whose relation to the relieved ammonium toxicity awaits further work. To summarize, these results suggest that there could be other parallel pathways that contribute to the alleviation of ammonium toxicity when adding nitrate (Table 1 ).

\section{Conclusion}

Extravagant use of ammonium fertilization affected the quality of $P$. notoginseng, and reduced the overall root biomass of $P$. notoginseng. In this study, we found that ammonium stress leads to the destruction of plasma membrane integrity in roots of $P$. notoginseng and the inhibition of root growth. Using both RNA-seq and qRT-PCR, we identified that $A C L A-3$ is up-regulated after introducing $\mathrm{NO}_{3}{ }^{-}$to $P$. notoginseng roots under $\mathrm{NH}_{4}{ }^{+}$stresses, which contributes to the recovery of root integrity and growth. These results offer new insight toward a better understanding on the mechanism of higher yield of $P$. notoginseng root, as well as other crops, when ammonium and nitrate fertilizer are simultaneously used.

\section{Materials and methods}

Plant material

Xiaohong $\mathrm{Ou}$ and Xiuming Cui undertook the formal identification of the plant material used in the study. Twoyear old $P$. notoginseng seedlings used for hydroponics were collected from the greenhouse of Faculty of Life
Science and Technology, Kunming University of Science and Technology $\left(24^{\circ} 51^{\prime} 0^{\prime \prime} \mathrm{N}, 102^{\circ} 52^{\prime} 2^{\prime \prime} \mathrm{E}\right.$, altitude $1835 \mathrm{~m})$, Yunnan, China by Xiaohong $\mathrm{Ou}$ and Peiran Liao. Seedlings with similar growing status were randomly selected for experiments.

\section{Sandy culture}

A pot with $10 \mathrm{~kg}$ quartz sand was used for a six months sandy culture. Four treatments with three replicates were selected, respectively were CK (Control); 15A (15 mM $\left.\mathrm{NH}_{4}{ }^{+}\right)$; $15 \mathrm{~N}\left(15 \mathrm{mM} \mathrm{NO}_{3}{ }^{-}\right)$; $15 \mathrm{AN}\left(15 \mathrm{mM} \mathrm{NH}_{4}{ }^{+}+15\right.$ $\mathrm{mM} \mathrm{NO}_{3}{ }^{-}$). Hoagland's solution was modified according to the $\mathrm{N}$ treatments, $\mathrm{NO}_{3}{ }^{-}$was replaced with $\mathrm{Ca}\left(\mathrm{NO}_{3}\right)_{2}$, $\mathrm{NH}_{4}{ }^{+}$was replaced with $\left(\mathrm{NH}_{4}\right)_{2} \mathrm{SO}_{4}, \mathrm{NH}_{4}{ }^{+}+\mathrm{NO}_{3}{ }^{-}$was replaced with $\mathrm{NH}_{4} \mathrm{NO}_{3}$. The final concentrations of the other macro-elements were $2.5 \mathrm{mM} \mathrm{K}_{2} \mathrm{SO}_{4}, 7.5 \mathrm{mM}$ $\mathrm{CaSO}_{4}, 1 \mathrm{mM} \mathrm{K}_{2} \mathrm{HPO}_{4}$, and $1 \mathrm{mM} \mathrm{MgSO}_{4}$. The final concentrations of micro-elements were $50 \mu \mathrm{M}$ EDTA-Fe, 7 $\mu \mathrm{M} \mathrm{Mn}, 0.7 \mu \mathrm{M} \mathrm{Zn}, 0.8 \mu \mathrm{M} \mathrm{Cu}, 2 \mu \mathrm{M}$ B, $0.8 \mu \mathrm{M}$ Mo. To prevent the nitrification of $\mathrm{NH}_{4}{ }^{+}, 7 \mu \mathrm{M}$ dicyandiamide (a nitrification inhibitor) was added in all solutions. The solution $\mathrm{pH}$ was adjusted within the range of 6.0-6.1. Each pot was poured $1 \mathrm{~L}$ solution every week, and transplanted eight 2-yr old seedlings, others were same with regular managements. After six months cultivation, all the seedlings were harvested to determine plant height, leaf length and width, hair root length, rhizoma diameter, root diameter and biomass by Xiaohong Ou and Peiran Liao.

\section{Hydroponic culture}

Xiaohong $\mathrm{Ou}$ and Peiran Liao used hydroponic culture to examine effects of different forms of nitrogen treatments on antioxidant system of $P$. notoginseng seedlings. Seedlings with similar growth vigor were washed off soil with tap water and washed three times with deionized water, then soaked in $2 \% \mathrm{NaClO}$ for $2 \mathrm{~h}$ and washed up $\mathrm{NaClO}$ with deionized water. After that, seedlings were pretreating with completely nutrient solution for one week, and the solution was renewed every two days. The composition of the nutrient solution was referred to Roosta et al. [54], containing $0.25 \mathrm{mM} \mathrm{NH}_{4} \mathrm{NO}_{3}, 0.2$ $\mathrm{mM} \mathrm{KH}_{2} \mathrm{PO}_{4}, 0.2 \mathrm{mM} \mathrm{K}_{2} \mathrm{SO}_{4}, 0.3 \mathrm{mM} \mathrm{CaSO}_{4}, 0.3 \mathrm{mM}$ $\mathrm{MgSO}_{4}, 50 \mu \mathrm{M}$ EDTA-Fe, $7 \mu \mathrm{M} \mathrm{MnSO}{ }_{4}, 0.7 \mu \mathrm{M} \mathrm{ZnCl}_{2}$, $0.8 \mu \mathrm{M} \mathrm{CuSO}_{4}, 2 \mu \mathrm{M} \mathrm{H}_{3} \mathrm{BO}_{3}, 0.8 \mu \mathrm{M} \mathrm{Na} \mathrm{MoO}_{4}$. The treatments and solutions composition of hydroponic culture were same with those of the sandy culture, which were CK (Control); 15A (15 $\left.\mathrm{mM} \mathrm{NH}_{4}{ }^{+}\right)$; $15 \mathrm{~N}$ (15 mM $\left.\mathrm{NO}_{3}{ }^{-}\right)$; and $15 \mathrm{AN}\left(15 \mathrm{mM} \mathrm{NH}_{4}{ }^{+}+15 \mathrm{mM} \mathrm{NO}_{3}{ }^{-}\right)$. Each treatment was replicated three times, and nutrient solution of each pot was renewed every two days. Six seedlings that pre-treated with above procedure were transplanted to each pot. On the third day, three seedlings of each treatment were harvested, then washed clean, divided into shoots and roots, frozen immediately with liquid 
nitrogen, stored at $-80^{\circ} \mathrm{C}$ for RNA extraction and metabolites determination. The hair roots of each seedling were used for root activity and plasma membrane integrity. In addition, the length of same hair root for each treatment was respectively measured on the first, third and fifth day.

\section{Examining root activity}

Root activity was analyzed by the triphenyl tetrazolium chloride (TTC) method [55] by Xiaohong Ou and Peiran Liao. TTC is a chemical that is reduced by dehydrogenases, mainly succinate dehydrogenase, when added to a tissue. The dehydrogenase activity is regarded as an index of the root activity. Briefly, approximately $0.5 \mathrm{~g}$ fresh root was immersed in $10 \mathrm{~mL}$ of equally mixed solution of $0.4 \%$ TTC and phosphate buffer, and kept in the dark at $37^{\circ} \mathrm{C}$ for $2 \mathrm{~h}$. Subsequently, $2 \mathrm{~mL}$ of $1 \mathrm{~mol} / \mathrm{L} \mathrm{H}_{2} \mathrm{SO}_{4}$ was added to stop the reaction with the root. The root was dried with filter paper and then extracted with ethyl acetate. The red extractant was transferred into the volumetric flask to reach $10 \mathrm{~mL}$ by adding ethyl acetate. The absorbance of the extract at $485 \mathrm{~nm}$ was recorded. Root activity was expressed as TTC reduction intensity. Formally, root activity was calculated with the following equation, $a=$ $r /(w \times t)$, where $a$ is root activity $(\mu \mathrm{g} /(\mathrm{g} \times \mathrm{h})), r$ is TTC reduction $(\mu \mathrm{g}), w$ is the fresh root weight $(\mathrm{g})$, and $t$ is time (h).

\section{Examining root plasma membrane integrity and relative root elongation}

Hair roots on the third day of treatments were used to examine the root plasma membrane integrity and relative root elongation by Xiaohong Ou and Peiran Liao. Evans blue staining indicates cell death, and the degree of staining in the root provides a semi-quantitative measurement of membrane permeability. Briefly, approximate one $\mathrm{cm}$ of the root tips were used for plasma membrane integrity by using the Evans-Blue (E-B) staining method [56]. Hair roots were thoroughly rinsed with deionized water, gently blotted and weighed. P. notoginseng root tips were stained with $0.5 \%(\mathrm{v} / \mathrm{v})$ E-B solution for $10 \mathrm{~min}$ at room temperature, rinsed three times with deionized water for a total of $10 \mathrm{~min}$ and photographed. Relative root elongation (\%) is calculated by (root length increment of treatment / root length increment of control) $\times 100 \%$.

\section{RNA extraction and sequencing}

Briefly, total RNA was extracted from each root tissue using the TRIzol reagent (Invitrogen, Thermo Fisher Scientific Inc., USA) and digested with DNase I (Takara, Dalian, China) according to the manufacturer's protocol. Then, the integrities of the RNAs were checked using an ultraviolet spectrophotometer (Hoefer, MA, USA), based on the ratio of the optical density at 260 $\mathrm{nm}$ to that at $280 \mathrm{~nm}(\mathrm{OD} 260 / 280=1.8-2.0)$. And total RNA were also assessed by electrophoresis in a agarose gel, which was visually judged the integrity of $18 \mathrm{~s}$ and $28 \mathrm{~s}$ ribosomal RNAs. After using an Agilent 2100 Bioanalyzer to determine the quality and concentration of each sample. The RNA-Seq libraries was constructed according to the manufacturer's suggestion. The RNA-Seq libraries were sequenced by Illumina Hiseq 2000 sequences at BGI, shenzhen, China. The obtained RNA-Seq profiles had been deposited to NCBI under GEO the accession number, GSE112437. The qualities of the obtained RNA-Seq profiles were evaluated with the FASTQC program (https://www.bioinformatics. babraham.ac.uk/projects/fastqc/).

\section{Bioinformatics analysis of RNA-seq profiles}

The raw reads of the datasets were aligned to the genome of $P$. notoginseng [21]. The reference genome [21] was built the index of using Bowtie2 v2.1.0 [57]. We used Tophat v2.0.13 [58] to align the sequencing reads to the reference genome [21] with the options of "-a 6 -r $50-G$ ". Then, Cufflinks (v2.2.1) was used to assemble, Cuffmerge (v2.2.1) was used to merge the transcriptomes with the options of "- 40", Cuffcompare (v2.2.1) was used to compared the self-assembled to the reported gene annotation with its default parameters [21], Cuffquant (v2.2.1) was used to calculate the gene expression levels with the options of "$\mathrm{u}-\mathrm{p} 4$ ", and Cuffnorm (v2.2.1) was used to normalize the gene expression levels as FPKM with the options of "-p 16" (Fragments Per Kilo basepairs per Million sequencing tags) [22]. The assembled genes were annotated by being aligned to the NCBI non-redundant nucleotide (Nt) database with BLASTN and NCBI non-redundant nucleotide protein $(\mathrm{Nr})$ database using BLASTX with the option of "-e 1E-5".

Gene expression levels under one of the groups with different treatments greater than 5 were used to perform Principal Component Analysis (PCA) analysis and clustering analysis. FPKM values plus one of genes were $\log 2$-scaled and then applied to the prcomp function in the psych library in $\mathrm{R}$ to perform PCA. Then the $\log 2$-scaled FPKM values of genes were used to calculate the correlation coefficient matrix of samples which was applied to the pheatmap function in the pheatmap library in $\mathrm{R}$ to perform hierarchical clustering of samples. The abundances of genes were compared to control to identify Differentially Expressed Genes (DEGs) using the edgeR package [23]. Genes with a FDR $<0.05$ values and fold change $\left|\log _{2} \mathrm{FC}\right|>1$ values were used as the significantly DEGs. We selected 117 up-regulated and 268 down-regulated genes under $15 \mathrm{~N}$ and $15 \mathrm{AN}$ treatments but not under $15 \mathrm{~A}$ treatment to perform a bi-clustering with the clustergram function in MatLab (MathWorks, Natick, MA, USA). KOBAS 3.0 was used to obtain Gene Ontology (GO) term and Kyoto Encyclopedia of Genes 
and Genomes (KEGG) pathway [59, 60]. The GO terms with multiple test corrected $P$-values $\leq 0.05$ and KEGG pathways with $P$-values $\leq 0.05$ were regarded as significantly enriched terms and pathways, respectively.

\section{Real-time PCR}

We collected roots of $P$. notoginseng plants grown in Kunming, Yunnan, China to validate the expression levels using the quantitative real-time PCR (qRT-PCR) experiments. On the third day of the hydroponic culture, three seedlings of each treatments were collected, root of each seedling was separated and frozen by liquid nitrogen, then stored at $-80{ }^{\circ} \mathrm{C}$. Total RNA extraction of each sample was same with that for sequencing. cDNA synthesis was referred to Livak et al. [61]. Briefly, $4 \mu \mathrm{g}$ of total RNA was mixed with $1 \mu \mathrm{l}$ of Oligo $\left(\mathrm{dT}_{18}\right)$ primer (Thermo, Thermo scientific technology, USA), 200 U of Revert Aid M-MuL Virus RT (Thermo) in the presence of $20 \mathrm{U}$ of RiboLock RNase inhibitor (Thermo). Oligonucleotide primers for genes were designed using Primer Express Software (Applied Biosystems, Foster City, CA). After RT, 20 ng of cDNA from the same cDNA batch was subjected to RT-PCR to amplify all genes in triplicate in a total reaction volume of $15 \mu \mathrm{l}$ using Roche SYBR Green Master mix (Roche, Basel, Swiss), and the required amount of forward and reverse primers. Reactions were conducted on a LightCycler (Roche, Roche Life Science, $\mathrm{CH}$ ) using the following cycling conditions: pre-incubation at $95^{\circ} \mathrm{C}$ for 10 min, 3-step amplification at $95^{\circ} \mathrm{C}$ for $10 \mathrm{sec}, 60^{\circ} \mathrm{C}$ for 30 sec, and $72^{\circ} \mathrm{C}$ for $1 \mathrm{~min}$. All samples were run in triplicate and each cDNA sample was run in duplicate. Expression of $P$. notoginseng $A C T 2$ was used as an internal control for target gene expression. The gene expression was calculated based on the $2^{-\Delta \Delta C t}$ method [61]. All the primer sequences of DEGs for real-time PCR were designed by Primer 5.0 software (Additional file 1: Table S28), and primers were synthesized by Tsingke Genomics Institute (Kunming, China).

\section{Assay method}

\section{$\mathrm{NH}_{4}{ }^{+}$determination}

$\mathrm{NH}_{4}{ }^{+}$concentration was determined according to Husted et al. [62]. $0.5 \mathrm{~g}$ fresh root tissue was homogenized with $5 \mathrm{ml}$ deionized water on ice, then centrifuged at $25,000 \mathrm{~g}\left(2^{\circ} \mathrm{C}\right)$ for $10 \mathrm{~min}$. The supernatant was used for $\mathrm{NH}_{4}^{+}$concentration determination by colorimetric.

\section{Amino acids determination}

Amino acids were measured by HPLC according to Geiger et al. [63]. Approximately $60 \mathrm{mg}$ root was placed in a screw cap tube and extracted sequentially for 15 min at $70^{\circ} \mathrm{C}$ with two $250 \mu \mathrm{l}$ of $80 \%$ aqueous ethanol (buffered with $10 \mathrm{mM}$ HEPES-KOH, pH 7.0), one $250 \mu \mathrm{l}$ of $50 \%$ aqueous ethanol (buffered with $10 \mathrm{mM}$ HEPES$\mathrm{KOH}, \mathrm{pH} 7.0$ ) and one $250 \mu \mathrm{l}$ of $10 \mathrm{mM}$ HEPES-KOH, $\mathrm{pH}$ 7.0. The extract was centrifuged between each step (5 min, 14,000 g). The supernatants were combined and measured by HPLC (Agilent 1120, Palo Alto, CA, USA).

\section{Carbohydrate determination}

Total soluble sugar concentration was determined by anthrone method according to Siddiqi et al. [64]. 0.5 g root sample was homogenized using a mortar and pestle with $10 \mathrm{ml}$ distilled water, then centrifuged at $1,000 \times \mathrm{g}$ for $10 \mathrm{~min}$, the supernatant was collected. After appropriate dilution of the supernatant, soluble sugar was colorimetric assayed at $630 \mathrm{~nm}$ by adding concentrated $\mathrm{HCl}, 45 \%$ formic acid, and anthrone/sulphuric acid solution.

Glucose and sucrose were measured by spectrophotometry method according to Stitt [65]. $0.5 \mathrm{~g}$ root sample was homogenized with $10 \mathrm{ml} 80 \%$ ethanol, then centrifuged at $3,000 \times \mathrm{g}$ for $10 \mathrm{~min}$. The supernatant was used for glucose and sucrose measurement.

\section{Organic acids determination}

$0.5 \mathrm{~g}$ fresh root sample homogenized with $1.5 \mathrm{ml} 5 \%$ trichloroacetic acid, centrifuged at $10,000 \times \mathrm{g}$ for $10 \mathrm{~min}$, supernatant was used for organic acids determination [25]. Organic acids analyzed by HPLC method with Aglient 1200 (USA) and an Intramax $(4.6 \mathrm{~mm} \cdot 250 \mathrm{~mm}$, $5 \mu \mathrm{m})$ column. Mobil phrase was $3 \%$ methanol $0.01 \mathrm{M}$ $\mathrm{K}_{2} \mathrm{HPO}_{4}(\mathrm{pH}=2.55)$, flow rate was $0.5 \mathrm{ml} \cdot \mathrm{min}^{-1}$, column temperature was $30^{\circ} \mathrm{C}$, injection volume was $10 \mu \mathrm{l}$, detective wavelength was $210 \mathrm{~nm}$ [66].

\section{Enzymatic assays}

Enzymatic assays were determined according to Sarasketa et al. [11]. Fresh roots were homogenized using a mortar and pestle with $20 \mu \mathrm{l}$ of extraction buffer per $\mathrm{mg}$ of $\mathrm{FW}[10$ $\mathrm{mM} \mathrm{MgCl}_{2}, 1 \mathrm{mM}$ EDTA, $1 \mathrm{mM}$ EGTA, $10 \mathrm{mM}$ dithiothreitol (DTT), $0.1 \%$ Triton X-100, 10\% glycerol, $0.05 \%$ bovine serum albumin (BSA), $0.5 \%$ polyvinylpolypyrrolidone (PVPP), $50 \mathrm{mM}$ HEPES pH 7.5] in the presence of a cocktail of proteases inhibitors [ $1 \mathrm{mM}$ phenylmethylsulfonyl fluoride (PMSF), $1 \mathrm{mM} \varepsilon$-aminocaproic acid, $10 \mu \mathrm{M}$ leupeptin]. Homogenates were then centrifuged at 4,000 g for $30 \mathrm{~min}$ at $4{ }^{\circ} \mathrm{C}$ and the supernatants recovered.

For phosphoenolpyruvate carboxylase (PEPC): $100 \mathrm{mM}$ Tricine- $\mathrm{KOH}(\mathrm{pH}=8), 5 \mathrm{mM} \mathrm{MgCl} 2,5 \mathrm{mM} \mathrm{NaF}, 0.25$ $\mathrm{mM}$ NADH, $6.4 \mathrm{U}$ of malate dehydrogenase $/ \mathrm{ml}, 2 \mathrm{mM}$ $\mathrm{NaHCO}_{3}$ and $3 \mathrm{mM}$ phosphoenolpyruvate; for $\mathrm{MDH}$ : $100 \mathrm{mM}$ HEPES-KOH (pH=7.5), $5 \mathrm{mM} \mathrm{MgSO} 4,0.2$ mM NADH, 2 mM oxaloacetate; for NADP-dependent isocitrate dehydrogenase (ICDH): $100 \mathrm{mM}$ Tricine- $\mathrm{KOH}$ $(\mathrm{pH}=8), 0.25 \mathrm{mM}$ NADP, $5 \mathrm{mM} \mathrm{MgCl}_{2}$, and $5 \mathrm{mM}$ isocitrate. 


\section{Statistical analysis}

All the data analyses were conducted with SPSS 18.0 (USA), Student's $t$-test was used to compare the significant difference between the data with CK or ammonium treating and that with nitrate or combination treating.

\section{Supplementary information}

Supplementary information accompanies this paper at

https://doi.org/10.1186/s12864-019-6340-7.

Additional file 1: Supplementary tables. This is an MS Excel file. This file includes 32 supplementary tables.

Additional file 2: Supplementary figures. This is a pdf file. This file includes 7 supplementary figures.

\section{Consent to publication}

Not applicable.

\section{Abbreviations}

ACLA-3: ATP-citrate lyase A-3; BSA: Bovine serum albumin; CK: Control; DEGs: Differentially expressed genes; DTT: Dithiothreitol; E-B: Evans-Blue ; FDR: False discovery rate; FPKM: Fragments per kilo basepairs per million sequencing tags; GO: Gene ontology; ICDH: NADP-dependent isocitrate dehydrogenase; KEGG: Kyoto encyclopedia of genes and genomes; P. notoginseng: Panax notoginseng; PCA: Principal component analysis; PEPC: Phosphoenolpyruvate carboxylase; PMSF: Phenylmethylsulfonyl fluoride; PVPP:

Polyvinylpolypyrrolidone; TTC: Triphenyl tetrazolium chloride

\section{Acknowledgements}

Not applicable.

\section{About this supplement}

This article has been published as part of BMC Genomics, Volume 20 Supplement 9, 2019: 18th International Conference on Bioinformatics. The full contents of the supplement are available at https://bmcgenomics. biomedcentral.com/articles/supplements/volume-20-supplement-9.

\section{Authors' contributions}

$Y Z, D L$ and $Y Y$ conceived and designed the research. $X O$ and $P L$ performed the biological experiments. $X O$ and $P L$ collected the samples and prepared RNA samples for sequencing. $S L, Y Y, Y Z, X C, D L$ and $P L$ analyzed the data. $Y Z, X O$, $S L, B Z$, and $Y Y$ wrote the manuscript. All authors have read and approved the manuscript.

\section{Funding}

Publication of this supplement was funded by two grants (No. 31460295 and 31760314) of National Natural Science Foundation of China (http://www.nsfc. gov.cn/) and a grant (No. SKLGE-1814) of the Open Research Funds of the State Key Laboratory of Genetic Engineering, Fudan University, China, to YZ, and grants (No. 2013FA031 and 2014FA003) of the Science and Technology Bureau of Yunnan Province to XC. The funders had no role in study design, data collection and analysis, decision to publish, or preparation of the manuscript.

\section{Availability of data and materials}

The datasets generated during and/or analyzed during the current study are available in the NCBI GEO database, https://www.ncbi.nlm.nih.gov/geo/query/ acc.cgi?acc $=$ GSE112437.

\section{Ethics approval and consent to participate}

Not applicable.

\section{Competing interests}

The authors declare that they have no competing interests.

\section{Author details}

${ }^{1}$ Kunming Key Laboratory of Sustainable Development and Utilization of Famous-Region Drug, Key Laboratory of Panax notoginseng Resources
Sustainable Development and Utilization of State Administration of Traditional Chinese Medicine, Faculty of Life Science and Technology, Kunming University of Science and Technology, Kunming 650500, China. ${ }^{2}$ Yunnan Key Lab of Primate Biomedicine Research; Institute of Primate Translational Medicine, Kunming University of Science and Technology, Kunming University of Science and Technology, Kunming 650500, China. ${ }^{3}$ Guizhou University of Traditional Chinese Medicine, Guiyang 550025, China. ${ }^{4}$ College of Pharmacy, Hubei University of Chinese Medicine, Wuhan 430065, China. ${ }^{5}$ State Key Laboratory of Genetic Engineering, Collaborative Innovation Center for Genetics and Development, Institute of Plant Biology, School of Life Sciences, Fudan University, Shanghai 200438, China.

Received: 20 November 2019 Accepted: 26 November 2019

Published online: 05 February 2020

\section{References}

1. Wang D, Zhu H, Chen K, Xu M, Zhang Y, Yang C. Saponin accumulation in the seedling root of panax notoginseng. Chin Med. 2011;6(1):5.

2. Xia P, Guo H, Zhao H, Jiao J, Deyholos MK, Yan X, Liu Y, Liang Z. Optima fertilizer application for panax notoginseng and effect of soil water on root rot disease and saponin contents. J Ginseng Res. 2016;40(1):38-46.

3. Wei W, Yang M, Liu Y, Huang H, Ye C, Zheng J, Guo C, Hao M, He X, Zhu S. Fertilizer $n$ application rate impacts plant-soil feedback in a sanqi production system. Sci Total Environ. 2018;633:796-807.

4. Sun XT, Lei L. I, Long GQ, Zhang GH, Meng Z. G, Yang SC, Chen JW. The progress and prospect on consecutive monoculture problems of panax notoginseng. Chin J Ecol. 2015;34(3):885-893.

5. Tan Y, Cui Y, Li H, Kuang A, Li X, Wei Y, Ji X. Rhizospheric soil and root endogenous fungal diversity and composition in response to continuous panax notoginseng cropping practices. Microbiol Res. 2017;194:10-19.

6. Dong L, Xu J, Feng G, Li X, Chen S. Soil bacterial and fungal community dynamics in relation to panax notoginseng death rate in a continuous cropping system. Sci Rep. 2016:6:31802.

7. Chen JL, Sun S. Z, Miao CP, Wu K, Chen Y.W, Xu LH, Guan HL, Zhao L. X. Endophytic trichoderma gamsii yim ph30019: a promising biocontro agent with hyperosmolar, mycoparasitism, and antagonistic activities of induced volatile organic compounds on root-rot pathogenic fungi of panax notoginseng. J Ginseng Res. 2016;40(4):315-24.

8. Hao Q, yan J, Liu D, Guo L, Huang L. The investigation of cultivation and processing technology of panax notoginseng from different producing areas. Mod Chin Med. 2014;16(2):123-9.

9. Cai-Yan D. U, Zhang N. M, Jiang R, Wang T, Liu Y, University YA. Evaluation of main soil nutrients characteristics for panax notoginseng planting area of yunnan. Southwest China J Agric Sci. 2016;29(3):599-607.

10. Britto DT, Kronzucker HJ. Nh4+ toxicity in higher plants: a critical review. Plant Physiol. 2002:159(6):567-84

11. Sarasketa A, González-Moro MB, González-Murua C, Marino D. Nitrogen source and external medium ph interaction differentially affects root and shoot metabolism in arabidopsis. Frontiers Plant Sci. 2016;7:29.

12. Esteban R, Ariz I, Cruz C, Moran JF. Review: Mechanisms of ammonium toxicity and the quest for tolerance. Plant Sci. 2016;248:92-101.

13. Zheng $X$, He $K$, Kleist $T$, Chen $F$, Luan S. Anion channel slah3 functions in nitrate-dependent alleviation of ammonium toxicity in arabidopsis. Plant Cell Environ. 2015;38(3):474-86.

14. Roosta HR, Schjoerring JK. Effects of nitrate and potassium on ammonium toxicity in cucumber plants. J Plant Nutrn. 2008;31(7):1270-83.

15. Yang $H$, von der Fecht-Bartenbach J, Friml J, Lohmann JU, Neuhäuser $B$ Ludewig $U$. Auxin-modulated root growth inhibition in arabidopsis thaliana seedlings with ammonium as the sole nitrogen source. Funct Plant Biol. 2015;42(3):239-51.

16. Takushi H, Watanabe CK, Masaru F, Toshiki I, Kentaro T, Maki KY, Hirofumi U, Yukifumi U, Ichiro T, Ko N. Nitrate addition alleviates ammonium toxicity without lessening ammonium accumulation, organic acid depletion and inorganic cation depletion in arabidopsis thaliana shoots. Plant Cell Physiol. 2012;53(3):577-91.

17. Yang SY, Hao DL, Song ZZ, Yang GZ, Wang L, Su YH. Rna-seq analysis of differentially expressed genes in rice under varied nitrogen supplies. Gene. 2015:555(2):305-17.

18. Sun L, Di D, Li G, Kronzucker HJ, Shi W. Spatio-temporal dynamics in global rice gene expression (oryza sativa I.) in response to high ammonium stress. J Plant Physiol. 2017;212:94-104. 
19. Yang H-C, Kan C-C, Hung T-H, Hsieh P-H, Wang S-Y, Hsieh W-Y, Hsieh $\mathrm{M}-\mathrm{H}$. Identification of early ammonium nitrate-responsive genes in rice roots. Sci Rep. 2017;7(1):16885.

20. Nunes-Nesi A, Fernie AR, Stitt M. Metabolic and signaling aspects underpinning the regulation of plant carbon nitrogen interactions. Mol Plant. 2010;3(6):973-96.

21. Chen W, Kui L, Zhang G, Zhu S, Zhang J, Wang X, Yang M, Huang H, Liu $Y$, Wang $Y$, et al. Whole-genome sequencing and analysis of the chinese herbal plant panax notoginseng. Mol Plant. 2017;10(6):899-902.

22. Trapnell C, Williams BA, Pertea G, Mortazavi A, Kwan G, Van Baren MJ, Salzberg SL, Wold BJ, Pachter L. Transcript assembly and quantification by rna-seq reveals unannotated transcripts and isoform switching during cell differentiation. Nat Biotechnol. 2010;28(5):511-5.

23. Robinson MD, McCarthy DJ, Smyth GK. edgeR: a Bioconductor package for differential expression analysis of digital gene expression data. Bioinformatics. 2010;26(1):139-40.

24. Esteban R, Ariz I, Cruz C, Moran JF. Mechanisms of ammonium toxicity and the quest for tolerance. Plant Sci. 2016;248:92-101.

25. Ariz I, Artola E, Asensio AC, Cruchaga S, Aparicio-Tejo PM, Moran JF. High irradiance increases nh4+ tolerance in pisum sativum: higher carbon and energy availability improve ion balance but not $n$ assimilation. J Plant Physiol. 2011;168(10):1009-15.

26. Ariz I, Asensio AC, Zamarreño AM, García-Mina JM, Aparicio-Tejo PM, Moran JF. Changes in the $\mathrm{c} / \mathrm{n}$ balance caused by increasing external ammonium concentrations are driven by carbon and energy availabilities during ammonium nutrition in pea plants: the key roles of asparagine synthetase and anaplerotic enzymes. Physiol Plant. 2013;148(4):522-37.

27. Balkos KD, Britto DT, Kronzucker HJ. Optimization of ammonium acquisition and metabolism by potassium in rice (oryza sativa I. CV. ir-72) Plant Cell Environ. 2010;33(1):23-34.

28. Hoopen Ft, Cuin TA, Pedas P, Hegelund JN, Shabala S, Schjoerring JK, Jahn TP. Competition between uptake of ammonium and potassium in barley and arabidopsis roots: molecular mechanisms and physiological consequences. J Exp Bot. 2010;61(9):2303-15.

29. Li Q, LI B-H, Kronzucker HJ, SHI W-M. Root growth inhibition by nh4+ in arabidopsis is mediated by the root tip and is linked to nh4+ efflux and gmpase activity. Plant Cell Environ. 2010;33(9):1529-42.

30. Liu Y, Lai N, Gao K, Chen F, Yuan L, Mi G. Ammonium inhibits primary root growth by reducing the length of meristem and elongation zone and decreasing elemental expansion rate in the root apex in arabidopsis thaliana. PLoS ONE. 2013;8(4):61031.

31. Lea $P$, Miflin B. Alternative route for nitrogen assimilation in higher plants Nature. 1974;251(5476):614

32. Vega-Mas I, Marino D, Sánchez-Zabala J, González-Murua C, Estavillo JM, González-Moro MB. Co2 enrichment modulates ammonium nutrition in tomato adjusting carbon and nitrogen metabolism to stomatal conductance. Plant Sci. 2015;241:32-44.

33. Lasa B, Frechilla S, Aparicio-Tejo PM, Lamsfus C. Role of glutamate dehydrogenase and phosphoenolpyruvate carboxylase activity in ammonium nutrition tolerance in roots. Plant Physiol Biochem. 2002;40(11):969-76.

34. Igamberdiev AU, Gardeström P. Regulation of nad-and nadp-dependent isocitrate dehydrogenases by reduction levels of pyridine nucleotides in mitochondria and cytosol of pea leaves. Biochim Biophys Acta (BBA)-Bioenerg. 2003;1606(1-3):117-25

35. Roosta H, Schjoerring JK. Root carbon enrichment alleviates ammonium toxicity in cucumber plants. J Plant Nutr. 2008;31(5):941-58.

36. Setién I, Fuertes-Mendizabal T, González A, Aparicio-Tejo PM, González-Murua C, González-Moro MB, Estavillo JM. High irradiance improves ammonium tolerance in wheat plants by increasing $n$ assimilation. J Plant Physiol. 2013;170(8):758-71.

37. Vega-Mas I, Pérez-Delgado CM, Marino D, Fuertes-Mendizábal T, González-Murua C, Márquez AJ, Betti M, Estavillo JM, González-Moro MB. Elevated $\mathrm{CO} 2$ induces root defensive mechanisms in tomato plants when dealing with ammonium toxicity. Plant Cell Physiol. 2017;58(12):2112-25.

38. Setién I, Vega-Mas I, Celestino N, Calleja-Cervantes ME, González-Murua C, Estavillo JM, González-Moro MB. Root phosphoenolpyruvate carboxylase and nad-malic enzymes activity increase the ammonium-assimilating capacity in tomato. J Plant Physiol. 2014;171(5): 49-63.
39. Gerendás J, Zhu Z, Bendixen R, Ratcliffe RG, Sattelmacher B. Physiological and biochemical processes related to ammonium toxicity in higher plants. J Plant Nutr Soil Sci. 1997;160(2):239-51.

40. Schortemeyer M, Stamp P, Feil B. Ammonium tolerance and carbohydrate status in maize cultivars. Ann Bot. 1997;79(1):25-30.

41. Ariz I, Esteban R, García-Plazaola JI, Becerril JM, Aparicio-Tejo PM, Moran JF. High irradiance induces photoprotective mechanisms and a positive effect on nh4+ stress in pisum sativum I. J Plant Physiol. 2010;167(13): 1038-45.

42. Siddiqi MY, Malhotra B, Min X, Glass AD. Effects of ammonium and inorganic carbon enrichment on growth and yield of a hydroponic tomato crop. J Plant Nutr Soil Sci. 2002;165(2):191-7.

43. Bialczyk J, Lechowski Z, Dziga D, Molenda K. Carbohydrate and free amino acid contents in tomato plants grown in media with bicarbonate and nitrate or ammonium. Acta Physiol Plant. 2005;27(4):523-9.

44. Fatland $\mathrm{BL}$, Ke J, Anderson MD, Mentzen WI, Cui LW, Allred CC, Johnston JL, Nikolau BJ, Wurtele ES. Molecular characterization of a heteromeric atp-citrate lyase that generates cytosolic acetyl-coenzyme a in arabidopsis. Plant Physiol. 2002;130(2):740-56.

45. Van Leene J, Hollunder J, Eeckhout D, Persiau G, Van De Slijke E, Stals H, Van Isterdael G, Verkest A, Neirynck S, Buffel Y, et al. Targeted interactomics reveals a complex core cell cycle machinery in arabidopsis thaliana. Mol Syst Biol. 2010;6(1):397.

46. Szczerba MW, Britto DT, Kronzucker HJ. Rapid, futile k+ cycling and pool-size dynamics define low-affinity potassium transport in barley. Plant Physiol. 2006;141(4):1494-507.

47. Hachiya T, Watanabe CK, Fujimoto M, Ishikawa T, Takahara K, Kawai-Yamada M, Uchimiya H, Uesono Y, Terashima I, Noguchi K. Nitrate addition alleviates ammonium toxicity without lessening ammonium accumulation, organic acid depletion and inorganic cation depletion in arabidopsis thaliana shoots. Plant Cell Physiol. 2012;53(3):577-91.

48. Rea PA. Plant atp-binding cassette transporters. Annu Rev Plant Biol. 2007;58:347-75

49. Geisler M, Murphy AS. The abc of auxin transport: the role of p-glycoproteins in plant development. FEBS Lett. 2006;580(4):1094-102.

50. Yang $\mathrm{H}$, Murphy AS. Functional expression and characterization of arabidopsis abcb, aux 1 and pin auxin transporters in schizosaccharomyces pombe. The Plant J. 2009;59(1):179-91.

51. Blakeslee JJ, Peer WA, Murphy AS. Auxin transport. Curr Opin Plant Biol. 2005;8(5):494-500.

52. Kretzschmar T, Burla B, Lee $Y$, Martinoia E, Nagy R. Functions of abc transporters in plants. Essays Biochem. 2011;50:145-60.

53. Rae GM, David K, Wood M. The dormancy marker drm1/arp associated with dormancy but a broader role in planta. Dev Biol J. 2013;2013: https://doi.org/10.1155/2013/632524.

54. Roosta HR, Schjoerring JK. Effects of ammonium toxicity on nitrogen metabolism and elemental profile of cucumber plants. J Plant Nutr. 2007;30(11):1933-51.

55. Zhang $X$, Huang G, Bian X, Zhao Q, et al. Effects of root interaction and nitrogen fertilization on the chlorophyll content, root activity, photosynthetic characteristics of intercropped soybean and microbial quantity in the rhizosphere. Plant Soil Environ. 2013;59(2):80-88.

56. Kan Q, Wu W, Yu W, Zhang J, Xu J, Rengel Z, Chen L, Cui X, Chen Q. Nitrate reductase-mediated no production enhances $c d$ accumulation in panax notoginseng roots by affecting root cell wall properties. J Plant Physiol. 2016;193:64-70.

57. Langmead B, Salzberg SL. Fast gapped-read alignment with bowtie 2 . Nat Methods. 2012;9(4):357-9.

58. Trapnell C, Pachter $L$, Salzberg SL. Tophat: discovering splice junctions with rna-seq. Bioinformatics. 2009;25(9):1105-11.

59. Wu J, Mao X, Cai T, Luo J, Wei L. Kobas server: a web-based platform for automated annotation and pathway identification. Nucleic Acids Res. 2006;34(suppl_2):720-4.

60. Xie C, Mao X, Huang J, Ding Y, Wu J, Dong S, Kong L, Gao G, Li C-Y, We L. Kobas 2.0: a web server for annotation and identification of enriched pathways and diseases. Nucleic Acids Res. 2011;39(suppl_2):316-22.

61. Livak KJ, Schmittgen TD. Analysis of relative gene expression data using real-time quantitative $P C R$ and the $2^{-\triangle \Delta C T}$ method. Methods. 2001;25(4):402-8.

62. Husted S, Hebbern CA, Mattsson M, Schjoerring JK. A critical experimental evaluation of methods for determination of nh4+ in plant tissue, xylem sap and apoplastic fluid. Physiol Plant. 2000;109(2):167-79. 
63. Geiger M, Walch-Liu P, Engels C, Harnecker J, Schulze E-D, Ludewig F, Sonnewald U, Scheible W-R, Stitt M. Enhanced carbon dioxide leads to a modified diurnal rhythm of nitrate reductase activity in older plants, and a large stimulation of nitrate reductase activity and higher levels of amino acids in young tobacco plants. Plant Cell Environ. 1998;21(3):253-68.

64. Siddiqi M, Kronzucker H, Britto D, Glass A. Growth of a tomato crop at reduced nutrient concentrations as a strategy to limit eutrophication. J Plant Nutr. 1998;21(9):1879-95.

65. Stitt M, Lilley RM, Gerhardt R, Heldt HW. Metabolite levels in specific cells and subcellular compartments of plant leaves. Methods Enzymol. 1989;174(1):518-52.

66. Gao H, Liao X, Wang S, Hu X. Simultaneous determination of eleven organic acids in fruit juice by reversed phase high performance liquid chromatography. Chin J Anal Chem. 2004;32(12):1645-8.

\section{Publisher's Note}

Springer Nature remains neutral with regard to jurisdictional claims in published maps and institutional affiliations.

- fast, convenient online submission

- thorough peer review by experienced researchers in your field

- rapid publication on acceptance

- support for research data, including large and complex data types

- gold Open Access which fosters wider collaboration and increased citations

- maximum visibility for your research: over $100 \mathrm{M}$ website views per year

At BMC, research is always in progress.

Learn more biomedcentral.com/submissions 